\title{
An Empirical Study on Relationship between Regional Logistics Industry Development and Economic Growth Based on Logistic Model
}

\author{
Xin Zou ${ }^{1, a}$, Brianna Smith ${ }^{2, b}$ \\ ${ }^{1}$ College of Management Science, Chengdu University of Technology, Chengdu 610059, China; \\ ${ }^{2}$ School of Medicine, James Cook University, Townsville 4811, Australia. \\ a872421412@qq.com, bbrianna.smith@my.jcu.edu.au
}

Keywords: regional logistics; economic growth; logistic model; empirical analysis

\begin{abstract}
By taking Sichuan Province as an example, the logistic model is used to analyze the quantitative relation between regional logistics industry development and regional economic growth. The promotional effect of logistics industry on economy in Sichuan is quantified through marginal utility analysis and elastic analysis. Finally, policy suggestions of promoting the development of modern logistics industry are proposed.
\end{abstract}

\section{Introduction}

Regional logistics refers to the logistics activity system with reasonable space structure and service scope established to comprehensively support the overall objective of regional sustainable development. It can adapt to regional environment characteristics, provide regional logistics function, meet the development demands of regional economy, politics, nature and military affairs, and realize effective organization and management ${ }^{[1]}$. The development of regional logistics can improve efficiency of regional economy by reducing transaction cost, supporting and promoting regional industry structure, and formation of new "growth pole"[2]. For a long time, numerous experts and scholars have done extensive research on the relation between regional logistics industry and regional economy. Danuta Kisperska-Moron $(1994)^{[3]}$ studied the relationship between economy and logistics during economic transition in Poland, and pointed out that logistics had an important promotion effect during economic transition periods. Wayne Talley (1996) ${ }^{[4]}$ established a quantitative model between logistics infrastructure investment and regional economic growth by applying a econometric model, using a qualitative analysis, he established a model for relevant influences of the service quality brought about by logistics infrastructure investment on regional economic development and logistics service. Tim Padmore et al. (1998) ${ }^{[5]}$ considered that the diffusing effect and backflow effect of logistics could form economies of scale outside the enterprise in the process of regional integration, stimulate industry innovation and technological spillover, and clarify the important effect of logistics industry on the promotion of regional economic growth. Keith G Debbage $(1999)^{[6]}$ studied the relation between logistics industry and regional economic growth from the angle of air transportation and regional economic development; this study showed that the association between economic changes and urban economy in Carolina of USA, could affect the development of air transportation industry, which had a causal relationship. Dennis Rondinelli et al. (2000) ${ }^{[7]}$ pointed out that with the rapid development, modern logistics service was bound to generate an important economic promotional effect. Heejoo Ham (2005) ${ }^{[8]}$ discovered through studies that rotation volume of freight transport and detail error in the freight transport process would affect the economy; they analyzed and summarized these influencial factors and predicted the scope of influence and the results. Therefore, regional logistics development and economic growth will promote, restrict and depend on each other. Based on this, a quantitative analysis is made for the relation between logistics industry development and economic growth in Sichuan via logistic model in this paper, so as to provide a scientific basis for further formulating a positive and suitable logistics industry policy. 


\section{Selection of Indices and Data}

(1) Regional economic growth index

According to the theory of economic growth, economic growth is mainly reflected as continuous increase of national output in "quantity" and reflected as the improvement of people's average life quality and overall progress of economic structure and social structure in "quality". "Quality" data of economic growth index cannot be gained easily, so the economic development situation is measured from the angle of "quantity" in this paper, and gross domestic product (GDP) is selected as the index of measuring economic growth.

(2) Regional logistics development index

Generally speaking, the development of logistics industry is mainly decided by the transportation, storage and logistics management level. In order to endow the model with operability, the total freight traffic is used to represent the developmental level of logistics when regional logistics development trend is predicted. These data can be acquired from statistical yearbooks of various regions and regional statistical information networks.

(3) Data sources

In this paper, data about GDP and total freight traffic from 2000 to 2013 in Sichuan are selected as samples (see Table 1). In order to provide convenience for follow-up calculation, each year is endowed with a time sequence number $(\mathrm{t}) 0 \sim 13$.

Table 1. Data table of GDP and Total Freight Traffic of Sichuan from 2000 to 2013

\begin{tabular}{cccc}
\hline Year & $\mathrm{t}$ & $\begin{array}{c}\text { GDP } \\
(100 \text { million CNY })\end{array}$ & $\begin{array}{c}\text { Total Freight Traffic } \\
(10,000 \text { tons })\end{array}$ \\
\hline 2000 & 0 & 3928.20 & 54943 \\
2001 & 1 & 4293.49 & 54141 \\
2002 & 2 & 4725.01 & 57297 \\
2003 & 3 & 5333.09 & 57200 \\
2004 & 4 & 6379.63 & 65580 \\
2005 & 5 & 7385.10 & 70364 \\
2006 & 6 & 8690.24 & 74200 \\
2007 & 7 & 10562.39 & 79940 \\
2008 & 8 & 12601.23 & 114513 \\
2009 & 9 & 14151.28 & 118094 \\
2010 & 10 & 17185.48 & 133364 \\
2011 & 11 & 21026.68 & 153827 \\
2012 & 12 & 23872.80 & 174451 \\
2013 & 13 & 26260.77 & 189611 \\
\hline
\end{tabular}

Data sources: Sichuan Statistical Yearbooks (2001-2014)

\section{Empirical Analysis of Relationship between Logistics Industry Development and Economic Growth of Sichuan}

\subsection{Modeling}

From the development process of logistics industry, its growth is reflected as S-shape growth form: It is initiated slowly at the beginning, then increases rapidly, and finally rises slowly and tends to be saturated. The characteristics of this phenomenon are described by a Logistic curve as follows: At the beginning, the growth is slow, later it is accelerated gradually, the growth rate declines gradually after reaching a certain level, and finally it approaches a horizontal line.

Statistical description is carried out for data about total freight traffic and GDP according to data in Table 1. A scatter diagram is drawn by setting total freight traffic (x) as horizontal axis and GDP (y) as vertical axis, as shown in Fig. 1. 


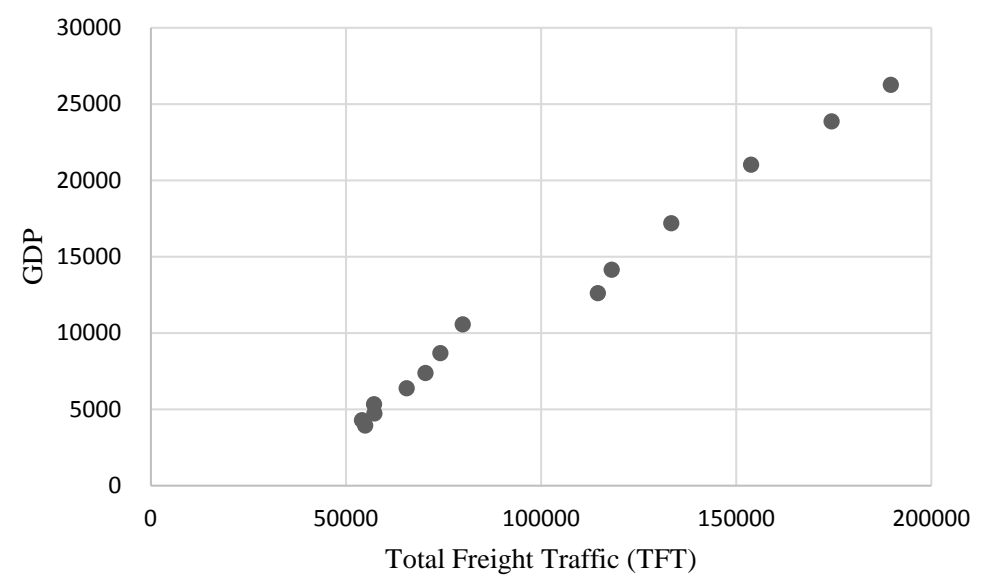

Fig. 1. Scatter diagram of relationship between Total Freight Traffic and GDP of Sichuan

It is preliminarily determined from the scatter diagram that the above two almost accord with the logistic model that describes economic growth trend. In another word, the function of these two is:

$$
y=\frac{1}{K+a b^{x}}
$$

In the formula, $y$ is GDP, $x$ means total freight traffic, and $K, a$ and $b$ are unknown constants and greater than $0 ; b \neq 1$.

In order to apply the parameter estimation method of linear function, the functional relation expression (1) is transformed, and the following formula is gained:

$$
\ln \left(\frac{1}{y}-K\right)=\ln a+x \ln b
$$

Make $\ln \left(\frac{1}{y}-K\right)=y^{\prime}, \quad \ln a=a^{\prime}, \ln b=b^{\prime}$

Then transform into:

$$
y^{\prime}=a^{\prime}+b^{\prime} x
$$

In this way, the values of parameters $a^{\prime}$ and $b^{\prime}$ in formula (2) can be estimated via least square method. As for the value of $K$, according to Logistic theoretical equation, when $0<b<1$ and $x \rightarrow \infty, K \rightarrow \frac{1}{y}$; in another word, $\frac{1}{K}$ is the saturation value of $y$. However in practical life, $x$ cannot tend to be infinitely great as total freight traffic and $y$ has no saturation value as regional GNP. Therefore, the predicted value of GDP in 2020 is set as the saturation value of GDP (y) to determine the parameters in this paper. According to this thought, time sequence analysis will be conducted for total freight traffic, GDP and between total freight traffic \& GDP.

\subsection{Time Series Analysis of Total Freight Traffic}

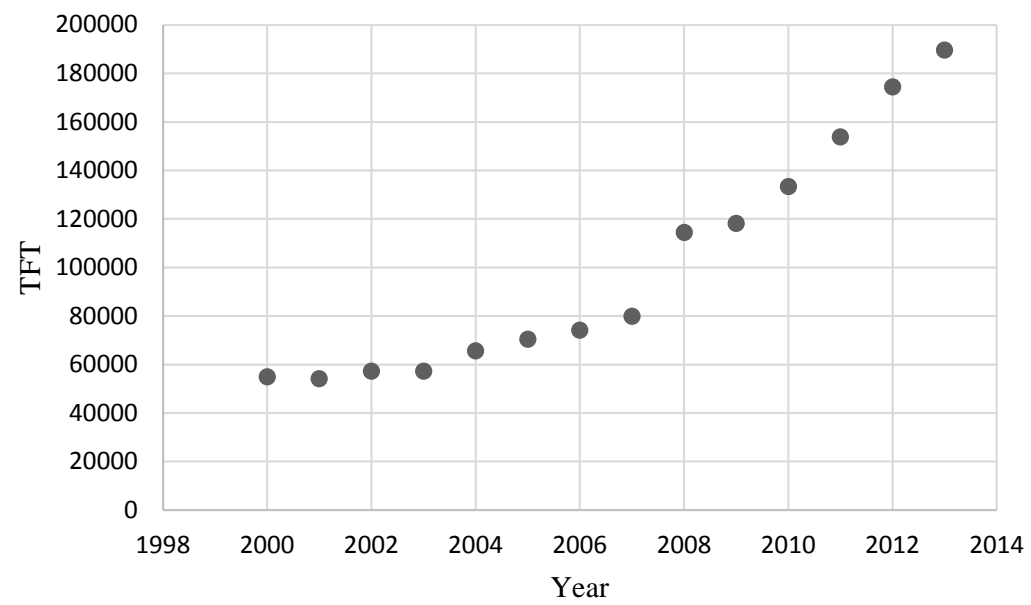

Fig. 2. Time series scatter diagram of Total Freight Traffic (TFT) 
A scatter diagram of annual total freight traffic in Sichuan from 2000 to 2013 is drawn according to Table 1. As per Fig. 2, total freight traffic presents an obvious rising trend with the increase of time, so we suppose that the total freight traffic satisfies the following model:

$$
y=a+b t
$$

In the formula, $y$ means total freight traffic (TFT), $t$ represents time sequence number, and $a$ and $b$ are unknown constants. The values of $a$ and $b$ are calculated via least square method by utilizing EViews 8 software. Thus:

Therefore:

$$
a=30155.09, \quad b=10718.17
$$

$$
y=30155.09+10718.17 t
$$

(3. 82) (10.39)

According to the analysis results of EViews, the fitting coefficient R-squared is 0.90 and the fitting degree is high. It is verified through table look-up that the simple linear regression model is significant after F-test and t-test, and the relation of regression equation is tenable.

The slope of the simple linear regression model is $10,718.17$, showing that the average total freight traffic of Sichuan in each year is 107.1817 million tons. Moreover, with the growth of economy and development of modern logistics industry, this value will continue to rise.

\subsection{Time Series Analysis of GDP}

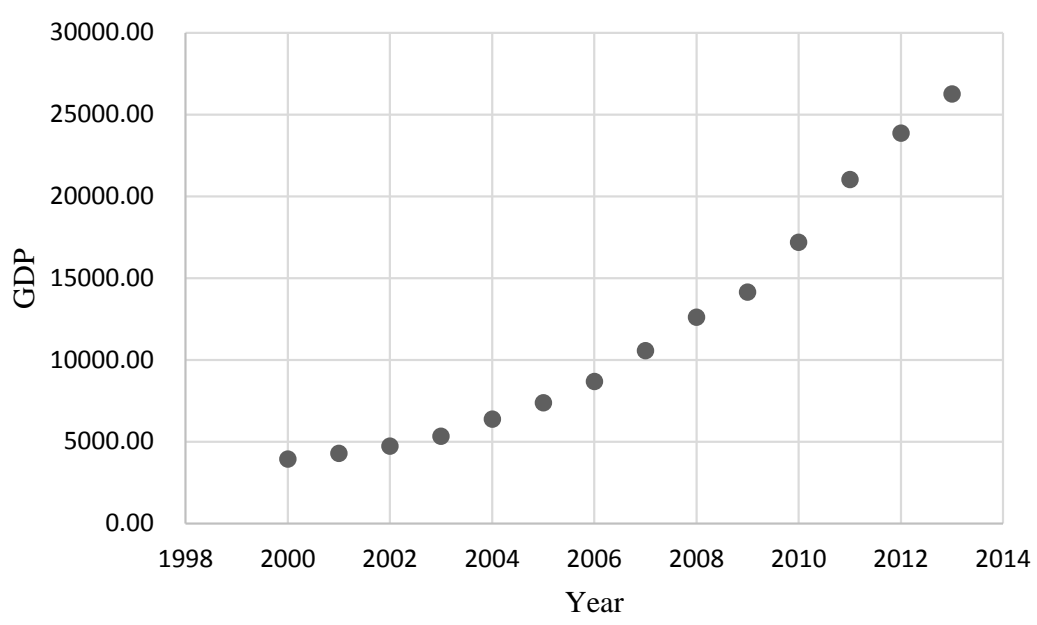

Fig. 2. Time series scatter diagram of GDP

A scatter diagram of annual GDP in Sichuan from 2000 to 2013 is drawn according to Table 1. As per Fig. 3, GDP presents an obvious rising trend with the increase of time, so we suppose that the GDP satisfies the following model:

$$
y=a+b t
$$

In the formula, $y$ means GDP, $t$ represents time sequence number, and $a$ and $b$ are unknown constants. The values of $a$ and $b$ are calculated via least square method by utilizing EViews 8 software. Thus:

Therefore:

$$
a=574.5797, \quad b=1740.124
$$

$$
y=574.5797+1740.124 t
$$

$$
\text { (0.52) (12.1) }
$$

According to the analysis results of EViews, the fitting coefficient R-squared is 0.92 and the fitting degree is high. It is verified through table look-up that the simple linear regression model is significant after F-test and t-test, and the relation of regression equation is tenable.

The slope of the simple linear regression model is $1,740.124$, showing that the average GDP of Sichuan in each year is $174,012.4$ million CNY. According to the regression model, the predicted value of GDP in $2020(t=20)$ is about 3,537,705,970,000 CNY in Sichuan. Here the "saturation value” of GDP is set as 3,600,000,000,000 CNY, i.e. $K=1 / 36000$. 


\subsection{Regression Test of Total Freight Traffic and GDP}

Regression test is conducted for total freight traffic with GDP according to data in Table 1.

According to the formula (2):

$$
y^{\prime}=a^{\prime}+b^{\prime} x
$$

In the formula: $y$ is GDP, $y^{\prime}=\ln \left(\frac{1}{y}-K\right), x$ means total freight traffic, and the results of values of $y^{\prime}$ are shown as Table 2:

Table 2. Values of $y$ ' in the process of regression test

\begin{tabular}{cccc}
\hline Year & GDP $(y)$ & TFT $(x)$ & $y^{\prime}$ \\
\hline 2000 & 3928.20 & 54943 & -8.3915 \\
2001 & 4293.49 & 54141 & -8.4919 \\
2002 & 4725.01 & 57297 & -8.6013 \\
2003 & 5333.09 & 57200 & -8.7420 \\
2004 & 6379.63 & 65580 & -8.9559 \\
2005 & 7385.10 & 70364 & -9.1368 \\
2006 & 8690.24 & 74200 & -9.3462 \\
2007 & 10562.39 & 79940 & -9.6123 \\
2008 & 12601.23 & 114513 & -9.8724 \\
2009 & 14151.28 & 118094 & -10.0569 \\
2010 & 17185.48 & 133364 & -10.4007 \\
2011 & 21026.68 & 153827 & -10.8308 \\
2012 & 23872.80 & 174451 & -11.1686 \\
2013 & 26260.77 & 189611 & -11.4832 \\
\hline
\end{tabular}

Regression of $y$ ' for the total freight traffic $x$ is conducted, and the result is as follows:

$$
a^{\prime}=-7.526154, \quad b^{\prime}=-0.0000213
$$

Therefore:

$$
\begin{array}{r}
y^{\prime}=-7.526154-0.0000213 x \\
(-64.84) \quad(-20.10)
\end{array}
$$

According to the analysis results of EViews, the fitting coefficient R-squared is 0.97 and the fitting degree is very high. It is verified through table look-up that the simple linear regression model is significant after F-test and t-test, and the relation of regression equation is tenable. Therefore, the following result can be gained:

$$
\left\{\begin{array}{l}
a=e^{a^{\prime}}=0.000539 \\
b=e^{b^{\prime}}=0.999979
\end{array}\right.
$$

Thereby, we suppose that the expression of Logistic model is:

$$
y=\frac{1}{\frac{1}{36000}+0.000539 \times 0.999979^{x}}
$$

The parameter test results are verified from the aspect of economics significance. $K=1 / 36000>0$, $a=0.000539>0$ and $0<b=0.999979 \neq 1$, which meet the economics rule that GDP rises with the increase of total freight traffic.

\subsection{Marginal Effect Analysis}

A derivative is taken with respect to $\mathrm{x}$ at both sides of formula (2), and the marginal effect of logistics industry on GDP in Sichuan can be gained:

$$
\frac{d y}{d x}=-a \ln b \frac{b^{x}}{\left(K+a b^{x}\right)^{2}}
$$

In the formula, $0<b<1$, so $\ln b<0$; meanwhile, $a>0$ and $b^{x}>0$, so $\frac{d y}{d x}>0$. This shows that GDP increases with the development of logistics industry in Sichuan. By substituting statistical data about the total freight traffic of 2013 in Sichuan into formula (3), we gain: 


$$
\frac{d y}{d x}=-0.000539 \times \ln 0.999979 \times \frac{0.999979^{189611}}{\left(\frac{1}{36000}+0.000539 \times 0.999979^{189611}\right)^{2}}=0.1475
$$

In other words, when the total freight traffic increases by 10,000 tons, GDP will rise by 14.75 million CNY. According to the above formula, $\frac{d y}{d x}>0$, but the second derivative:

$$
\frac{d^{2} y}{d x^{2}}=-a(\ln b)^{2} \frac{b^{x}}{\left(K+a b^{x}\right)^{2}}\left[1-\frac{2 a b^{x}}{K+a b^{x}}\right]
$$

By solving the equation $\frac{d^{2} y}{d x^{2}}=0$, we gain that the stationary point is $x=141211.8139$. When $x<141211.8139, \frac{d^{2} y}{d x^{2}}>0$; when $x>141211.8139, \frac{d^{2} y}{d x^{2}}<0$. This means that the contribution of total freight traffic to GDP can be divided into two stages. When the total freight traffic is smaller than 1,412,118,139 tons, the growth amount of GDP brought about by the increase of logistics industry by 1 unit, rises continuously with the increase of logistics scale; when the total freight traffic is greater than 1,412,118,139 tons, the growth amount of GDP brought about by the increase of logistics industry by 1 unit, reaches the maximum value. The total freight traffic of 2011 in Sichuan is 1,538,270,000 tons (exceeding the value of 1,412,118,139 tons), which means that the promotion effect of logistics industry on GDP presents a trend of slowing down in Sichuan. At this time, logistics industry cannot fully express its function in regional GDP growth. Therefore, logistics industry of Sichuan should accelerate its transformation to high-end logistics pattern, so as to drive continuous and healthy development of the industry.

\subsection{Elastic Analysis}

The effect ratio of regional logistics industry on economy is found through elastic analysis, which means to find the change percentage of GDP when logistics industry changes by $1 \%$. According to formula (3), the elastic coefficient of logistics industry for GDP in Sichuan can be obtained:

$$
\xi=\frac{d y}{d x} \cdot \frac{x}{y}=\frac{-a b^{x} \ln b}{\left(K+a b^{x}\right)^{2}} \cdot \frac{x}{\frac{1}{K+a b^{x}}}=-a \ln b \frac{x b^{x}}{K+a b^{x}}
$$

In the formula, $\xi$ means that when logistics industry rises by one percentage point in Sichuan, the growth rate of GDP will be promoted. $a>0,0<b<1, \ln b<0$, and $x, K$ and $b^{x}$ are greater than 0 , so the elastic coefficient $\xi>0$. Therefore, GDP changes with logistics industry at the same direction. In another word, when logistics industry increases, GDP also rises, and vice versa. The following formula can be gained after calculation according to data of 2013 in Table 1:

$$
\xi=-0.000539 \times \ln 0.999979 \times \frac{189611 \times 0.999979^{189611}}{\frac{1}{36000}+0.000539 \times 0.999979^{189611}}=1.0581
$$

The results show that when the total freight traffic is 1,896,110,000 tons, GDP will rise by $1.0581 \%$ if the total freight traffic increases by $1 \%$. In another words, economic growth is slightly faster than the increase of logistics industry. According to this figure, logistics demand and logistics supply capacity are almost the same in Sichuan, and logistics industry has an obvious promotional effect on economic growth.

\section{Conclusion and Suggestion}

In this paper, an empirical analysis is made for the interactive relationship between regional logistics development and economic growth in Sichuan via the Logistic model. According to the results, logistics industrial development and economic growth in Sichuan have a long-term and stable equilibrium relation. Besides, logistics industrial development has an obvious promotional effect on economic growth, and different development characteristics will be presented at different 
stages. However in recent years, with the expansion of logistics scale, its contribution to economic growth is been gradually weakened. As for the reasons, government departments have overemphasized the construction of logistics infrastructure and ignored the fact that it has exceeded the current demand of economic development in recent years. By simply relying on the extensive growth pattern, logistics industry cannot express its function of promoting economic growth to the largest extent. In order to further strengthen the interaction between logistics industry development and economic growth to realize harmonious development between logistics industry and economy, the following suggestions are proposed:

\subsection{To Make the Government Play a Positive Guidance and Promotion Role}

Firstly, governments at all levels should increase the capital investment in logistics industry, and positively study, formulate and implement various supportive polices. Meanwhile, they need to learn from the advanced experience of developed countries and the practice of other provinces and cities. Secondly, government departments should strengthen planning and guidance for modern logistics industry, and intensify measures of charge management by adjusting the current administrative management mode, perfecting tax administration of logistics enterprises, and standardizing the market order, so as to create a good environment for the development of modern logistics industry. Finally, cultivation for multilevel professional logistics talent and introduction of advanced logistics management talent must be strengthened. At the same time, corresponding financial support policies should be provided to promote sound development of logistics industry.

\subsection{To Accelerate Establishment for Public Information Platform of Logistics}

Public information platform of logistics has provided a powerful support for the development of modern logistics industry. Its major function is to form a standard and shared information platform by integrating social logistics information resources in the whole province and generate a national public information platform of logistics by connecting to public information platforms of other provinces and cities ${ }^{[14]}$. In the future, the fourth-party logistics platform should be set as the core, and construction for public information platform of logistics must be accelerated. Enterprise information, government information and social information can be integrated through the platform, and sharing of logistics information resources will be realized. In this way, the logistics cost can be reduced, smooth logistics will be guaranteed, and logistics efficiency and economic benefit can be improved.

\subsection{To Strengthen Cultivation for Professional Logistics Talent}

With refining and full-process development of modern logistics, as well as extensive application of information technology in logistics field, the demand for professional logistics talent becomes more in logistics field and the requirement for knowledge and skill level is also emphasized. Therefore, cultivation for professional logistics talent and introduction of advanced logistics management talent must be strengthened. Meanwhile, a set of professional, comprehensive and social logistics talent training systems should be constructed, and preferential policies of introducing advanced talent must be formulated. At the same time, colleges and universities should adapt to the industrialization development demand of logistics, strengthen cooperation with enterprises, and gradually form a training mode of industry-university-research cooperation, so as to cultivate high-quality versatile talent for modern logistics industry. On the other hand, cultivation for existing employees should be strengthened. The professional capacity and ability of employees can be improved through multilevel and multiform training such as interviews and on-the-job training.

\section{References}

[1] LIU Yan. Study on the Relationship of Regional Logistics Supply and Demand Based on DEA. Master's thesis, Beijing Jiaotong University, Beijing, 2009. (in Chinese)

[2] ZHANG Jian-sheng, HU Xiu-zhong. Research on Coupling Harmony between Regional Logistics and Regional Economics. Railway Transport and Economy 2012, 34(1), 50-55. (in Chinese) 
[3] Danuta Kisperska-Moron. Logistics change during the transition period in the Polish economy. International Journal of Production Economics 1994, 35(1), 23-28.

[4] Wayne Talley. Linkages between transportation infrastructure investment and economic production. Logistics and Transportation Review 1996, 32(1), 145-154.

[5] Tim Padmore, Hervey Gibson. Modelling systems of innovation:: II. A framework for industrial cluster analysis in regions. Research Policy 1998, 26(6), 625-641.

[6] Keith G Debbage. Air transportation and urban-economic restructuring: competitive advantage in the US Carolinas. Journal of Air Transport Management 1999, 5(4), 211-221.

[7] Dennis Rondinelli, Michael Berry. Multimodal transportation, logistics, and the environment: managing interactions in a global economy. European Management Journal 2000, 18(4), 398-410.

[8] Heejoo Ham, Tschangho John Kim, David Boyce. Assessment of economic impacts from unexpected events with an interregional commodity flow and multimodal transportation network model. Transportation Research Part A: Policy and Practice 2005, 39(10), 849-860.

[9] GAO Xiu-li, WANG Ai-hu, FANG Xing-chao. An Empirical Research on the Relationship between Regional Logistics and Regional Economic Growth in Guangdong Province. Industrial Engineering Journal 2012, 15(1), 60-65. (in Chinese)

[10]ZHOU Jun. Analysis on the Impact of Regional Logistics Industry on Regional Economic Growth. Statistics and Decision 2006, (4), 109-112. (in Chinese)

[11] HUANG Hao, HUANG Wei. Empirical Study on Relationship between Logistics Industry and Economic Growth of Wuhan Based on Logistic Model. Logistics Technology 2015, 34(5), 197-199. (in Chinese)

[12]LI Ai-bin, ZHAO Pian-pian. Empirical Research on the Relationship between Logistics Industry and Economic Growrh in Xuzhou. Journal of Industrial Technological Economics 2011, 30(9), 77-82. (in Chinese)

[13]ZOU Xin, ZHANG Meng-qin. Forecasting of Logistics Demand of Sichuan Based on GM(1,1). Logistics Technology 2015, 34(9), 166-169. (in Chinese)

[14]ZUO Hong. Investigation Report of Hunan Logistics Public Information Platform. Logistics Sci-Tech 2013, 36(2), 24-27. (in Chinese) 